\title{
Unconventional Answers to Unprecedented Challenges: The Swedish Experience During the COVID-19 Outbreak
}

\author{
Giuseppe Valeriani ${ }^{1}$, Iris Sarajlic Vukovic ${ }^{2}$, Richard Mollica ${ }^{3}$ \\ ${ }^{1}$ Refugee Health Centre, Ostergotland County Council, Norrkoping, Sweden; ${ }^{2}$ Sahlgrenska University Hospital, Affective Psychiatry, Gothenburg, \\ Sweden; ${ }^{3}$ Harvard Program in Refugee Trauma, Massachusetts General Hospital, Harvard Medical School, Cambridge, MA, USA
}

Since its early stages, the coronavirus disease 2019 (COVID-19) pandemic has posed immense challenges in meeting the public health and healthcare and social care needs of migrants. In line with other reports from United Kingdom and United States, data from Sweden's health authority show that migrants have been disproportionately affected by COVID-19. Following the World Health Organization's statements, as well as the European Public Health Association's call for action, several centres in Sweden's most populated areas have activated tools to implement national plans for community outreach through initiatives targeting migrants and ethnic minority groups. Unconventional means should be promoted to mitigate the impact of COVID-19 on migrants and the health of the public at large.

Key words: COVID-19, Healthcare delivery, Migrants, Telemedicine, Community health

Public health interventions, clinical care, and social care to address the needs of minorities such as migrants and certain ethnic or racial groups have become urgent concerns as part of the response to coronavirus disease 2019 (COVID-19), which the World Health Organization (WHO) declared a pandemic on March 11, 2020 [1]. A few days after the WHO statement, on March 24, 2020, the Migrant and Ethnic Health Section of the European Public Health Association encouraged all health professionals to act together to reduce the impact of the coronavirus crisis on those "left behind"—-disadvantaged migrants and ethnic minorities [2]. Similarly, other international organizations, such as the Platform for International Cooperation on Undocumented Migrants, non-governmental organizations, and acknowledged experts in public health released state-

Received: May 28, 2020 Accepted: July 22, 2020

Corresponding author: Giuseppe Valeriani, MD

Refugee Health Centre, Ostergotland County Council, 116 Slottsgatan,

Norrkoping 60182, Sweden

E-mail: giuseppe.valeriani@sll.se

This is an Open Access article distributed under the terms of the Creative Commons Attribution Non-Commercial License (https://creativecommons.org/licenses/bync/4.0/) which permits unrestricted non-commercial use, distribution, and reproduction in any medium, provided the original work is properly cited. ments setting out the immense necessity of actions to protect refugees and undocumented migrants [3].

Despite these efforts, severe consequences of COVID-19, including mortality, have followed in several Western countries. As the Centers for Disease Control and Prevention reported [4], ethnic minorities, Black people, and Asians are disproportionally affected by COVID-19 due to socioeconomic differences, a tendency that has been especially noted in the United Kingdom and United States [5]. In Sweden, a similar trend has significantly affected the Stockholm region. According to data from the local medical authority (Smittskydd Stockholm) for the period up to May 19, 2020, in Rinkeby-Kista, an area north of Stockholm where over $80 \%$ of residents are first-generation or second-generation migrants, with the large majority coming from Somalia and Eritrea, 90 COVID-19 cases and 16.7 COVID-19-related deaths per 10000 inhabitants were reported. These are the highest rates in the entire region, where overall 44 COVID-19 cases and 7.7 COVID-19-related deaths per 10 000 inhabitants were reported. The second highest number of registered cases was in Spånga-Tensta. In this borough, located north-west of Stockholm, where about $60 \%$ of inhabitants are foreign-born and come mostly from the Middle East, the 
local authority registered 71 cases and 12 deaths per 10000 inhabitants [6]. These areas are also characterized by socioeconomic deprivation, overcrowded living conditions, and linguistic obstacles in adopting preventative measures. Moreover, this population is more often exposed to critical work conditions such as working in public transportation, home care, and retirement homes caring for the elderly, without the possibility of working from home. During the same period, in the second biggest city in Sweden, Gothenburg, the east part of the city is overrepresented compared to the other parts of the city. As reported by the local authority, that area has registered 43 cases per 10000 inhabitants, which is over 50\% higher than the average rate in Gothenburg of 29 cases per 10000 [7]. In the cited area, over $40 \%$ of the population is composed of firstgeneration or second-generation migrants, with Iraq as the most represented foreign country of birth.

Although official data about the spread of COVID-19 among undocumented migrants are missing, their living conditions generally involve no suitable environment to observe the 2-m precautionary measure (the main measure to prevent direct person-to-person transmission of severe acute respiratory syndrome coronavirus 2 [SARS-CoV-2]) and other social distancing guidance, and there are no established means for communicating information to them through the public sector. This represents a major concern among public health providers. Alongside these factors, as Bhopal remarks, there is no prior bond of trust of undocumented migrants with the statutory authorities [3]; this has an especially severe effect in a country such as Sweden, where the government has invested its efforts into establishing mutual trust between citizens and authorities regarding preventive health measures instead of implementing compulsory orders to stay at home. Moreover, even though the Swedish legislation ensures to all foreign persons, independently from migrant status, inclusion in national programmes for health promotion, disease prevention, treatment, and care, undocumented migrants present to healthcare centres to a lesser extent than the rest of the population, because of the fear of links between caregivers and police.

The COVID-19 outbreak poses immense challenges, demanding reduction of healthcare inequities at a rapid pace. On April 17, 2020, the WHO stated its guiding principles and recommendations in order to improve community engagement of migrants in the campaign to face the health threats posed by COVID-19 [8]. While some principles are finalised through the review of national preparedness and response plans, at a local level the need is emphasised to support measures to improve communication and counter xenophobia; to provide culturally and linguistically appropriate, accurate, timely and user-friendly information in accessible formats on health facilities; and to identify and work with groups able to communicate well with refugees and migrants. Following this statement, since the end of April 2020, several healthcare centres in Stockholm, Gothenburg, and other main cities in Sweden have activated services by phone (so called "corona lines") in order to deploy the existing national phone lines to reach a considerable number of migrants. Experienced healthcare professionals fluent in different languages (Arabic, Somali, Persian/Dari, Tigrinya/Amharic) are available to provide information including preventive measures and triage of those with respiratory symptoms, as well as home care and individual and community hygiene. By using initiatives targeting specific communities (e.g., multilingual pamphlets, videos shared on Facebook by community groups, posters in community centres), these phone lines can spread and enhance the provision of information among minority populations. In addition, when working with immigrant and ethno-cultural minority clients, clinicians should be open to clients seeking support from non-medical sources, such as religious or spiritual groups; therefore, liaising with local religious leaders also. should be urgently considered by physicians. All of the previously mentioned factors are important in adopting preventative measures.

We think that in this critical health crisis, every possible solution needs to be considered in order to address the needs of those who are most disadvantaged. Outreach should involve identifying those in need, such as people with underlying chronic diseases, the elderly, and migrants, with consideration of all specific characteristics of these subgroups. Investing in phone line services together with a culturally appropriate approach to diverse sources addresses 3 main goals: (1) to raise awareness among ethnic minority groups regarding the needed changes in habits due to the pandemic; (2) to decrease migrants' barriers to access to health services (e.g., uncertainty regarding legal entitlements to healthcare, the fear of being reported and deported, and language difficulties); and (3) to give support that strengthens social cohesion, solidarity, and healthy coping, and reduces loneliness. This approach, in our opinion, may be further integrated by ongoing global task forces aimed to implement telemedicine as a tool that can bridge distances in the situation of the pandemic [9]. Using 
video-links for needed treatment and/or psychosocial help should be recommended in primary care services. In this way, preparedness and response plans considering minorities, migrants, and refugees may mitigate the impact of COVID-19, which can, in turn, affect public health at large.

In order to achieve the mission of public health, accurate, complete, and timely information must be provided through various means, regardless of the conventionality of instruments for community outreach. Addressing migrant and refugee health needs should be an urgent public health priority or the consequences can be dire. This approach is of the utmost importance, as there can be no public health without refugee and migrant health [10].

\section{Ethics Statement}

This paper is a perspective, so it did not need ethical approval.

\section{CONFLICT OF INTEREST}

The authors have no conflicts of interest associated with the material presented in this paper.

\section{FUNDING}

None.

\section{ACKNOWLEDGMENTS}

The authors thank the Swedish Public Health Authority Folkhalsomyndigheten for collecting the data presented in this manuscript. The authors thank also Ela Vuković (University of Gothenburg) for valuable reflections and text translations.

\section{AUTHOR CONTRIBUTIONS}

Conceptualization: GV, ISV, RM. Data curation: GV, ISV. Funding acquisition: None. Writing - original draft: GV. Writing - review \& editing: ISV, RM.

\section{ORCID}

Giuseppe Valeriani https://orcid.org/0000-0002-5829-7682 Iris Sarajlic Vukovic https://orcid.org/0000-0002-4803-1979 Richard Mollica https://orcid.org/0000-0002-8094-1390

\section{REFERENCES}

1. World Health Organization. WHO announces COVID-19 outbreak a pandemic [cited 2020 May 19]. Available from: http:// www.euro.who.int/en/health-topics/health-emergencies/ coronavirus-covid-19/news/news/2020/3/who-announcescovid-19-outbreak-a-pandemic.

2. European Public Health Association (EUPHA). Statement by the EUPHA migrant and ethnic minority health section on COVID-19 - call for action [cited 2020 May 16]. Available from: https://eupha.org/repository/advocacy/MIG_statement_on_ COVID19.pdf.

3. Bhopal RS. COVID-19: immense necessity and challenges in meeting the needs of minorities, especially asylum seekers and undocumented migrants. Public Health 2020;182:161-162.

4. Centers for Disease Control and Prevention. COVID-19 in racial and ethnic minority groups [cited 2020 May 12]. Available from: https://www.cdc.gov/coronavirus/2019-ncov/need-extra-precautions/racial-ethnic-minorities.html.

5. Abuelgasim E, Saw LJ, Shirke M, Zeinah M, Harky A. COVID-19: unique public health issues facing Black, Asian and minority ethnic communities. Curr Probl Cardiol 2020;45(8):100621.

6. Vårdgivarguiden är Region Stockholms. Number of infected and deceased with COVID-19 per municipality/district [cited 2020 May 21]. Available from: https://vardgivarguiden.se/nyheter/2020/maj/19-maj-antal-smittade-och-avlidna-perkommun-stadsdel/ (Swedish).

7. Västra Götalandsregionen. Current statistics on COVID-19 in Västra Götaland [cited 2020 May 20]. Available from: https:// www.vgregion.se/covid-19-corona/statistik-covid-19-i-vastra-gotaland/ (Swedish).

8. World Health Organization. Preparedness, prevention and control of coronavirus disease (COVID-19) for refugees and migrants in non-camp settings [cited 2020 May 19]. Available from: https://www.who.int/publications-detail/preparedness-prevention-and-control-of-coronavirus-disease-(covid-19)-for-refugees-and-migrants-in-non-camp-settings.

9. Ohannessian R, Duong TA, Odone A. Global telemedicine implementation and integration within health systems to fight the COVID-19 pandemic: a call to action. JMIR Public Health Surveill 2020;6(2):e18810.

10. Kluge HH, Jakab Z, Bartovic J, D'Anna V, Severoni S. Refugee and migrant health in the COVID-19 response. Lancet 2020; 395(10232):1237-1239. 